\title{
Mass Spectrometric Identification of Chemical Warfare Agent Adducts with Biological Macromolecule for Verification of Their Exposure
}

\author{
Kouichiro Tsuge* and Yasuo Seto \\ National Research Institute of Police Science, 6-3-1 Kashiwanoha, Kashiwa, Chiba 277-0882, Japan
}

(Received November 17, 2008)

\begin{abstract}
Exposure to chemical warfare agents (CWAs) can be verified by detecting their degradation products in biological samples. However, the half-lives of these CWA degradation products in the body are short. CWAs are known to combine with biological macromolecules and the covalently bound compounds are called adducts. The residence time of adducts in the human body is longer than that of the corresponding CWA degradation products. Therefore, development of analytical methods to detect these adducts is a more realistic way of verifying CWA exposure. In this mini review, we describe the present state of research on analytical methods for identifying CWA adducts, and mainly introduce our research on nerve gas adducts using a direct method. Novel analytical methods for verifying low level exposure to nerve gases use liquid chromatography-mass spectrometry (LC-MS). Butyrylcholinesterase $(\mathrm{BuChE})$ has been purified by affinity chromatography and sodium dodecylsulfate poly-acrylamide gel electrophoresis. The purified enzyme is inhibited by nerve gases (sarin, VX and soman) and digested by chymotrypsin, and then the peptides are analyzed by LC-MS and LC tandem MS. The peptide fragment that is combined with nerve gas is detected by LC-MS. Furthermore, the chemical structure of the adduct peptide characterized by MS provides structural information about the analyte. The detection limit of BuChE or BuChE adduct is estimated at $4 \mathrm{ng} /$ injection ( $53 \mathrm{fmol} /$ injection). If at least $1 \%$ of BuChE activity is inhibited by nerve gas, the adduct can be detected at a level of $1 \%$ BuChE inhibition in the victim's serum.
\end{abstract}

Key words — chemical warfare agent, adduct, liquid chromatography-mass spectrometry

\section{INTRODUCTION}

The Matsumoto and Tokyo subway system sarin gas attacks in 1994 and 1995 remind us that terrorists have used chemical warfare agents (CWAs) against civilians. When CWAs are used for terrorism and homicide, rapid and accurate identification is needed for management of the incident and its consequences, such as emergency medical treatment and criminal investigation. ${ }^{1)}$

Various chemicals have been used as CWAs. In World War I (WWI), chlorine gas was used in munitions for the first time, as a choking agent, by the German army, another choking agent, phosgene was also used. To protect soldiers from the effects of such agents, gas masks were introduced,

\footnotetext{
${ }^{*}$ To whom correspondence should be addressed: National Research Institute of Police Science, 6-3-1 Kashiwanoha, Kashiwa, Chiba 277-0882, Japan. Tel.: +81-4-7135-8001; Fax: +81-4-7133-9173; E-mail: tuge@nrips.go.jp
}

then to circumvent the defenses afforded by gas masks, a mustard gas called Yperite was developed. This blister agent is more toxic than choking agents, especially after skin exposure. Hydrogen cyanide, cyanogen chloride and arsine are categorized as blood agents. After WWI, new classes of CWAs were developed in an attempt to render gas masks ineffective: diphenylchloroarsine, diphenylcyanoarsine and adamsite, which are categorized as vomiting agents. Figure 1 shows the chemical structure of these CWAs. Blister agents, choking agents, tear gases and blood agents were formerly used by the Japanese military, and were left behind not only in China, but also in Japan during World War II (WWII). In Germany, extremely toxic organophosphorus compounds called G-type nerve gases were developed from insecticides (Fig. 2). These agents exert a fatal effect by obstructing the nervous system. A treaty prohibiting the development, production, stockpiling, or use of chemical weapons and 


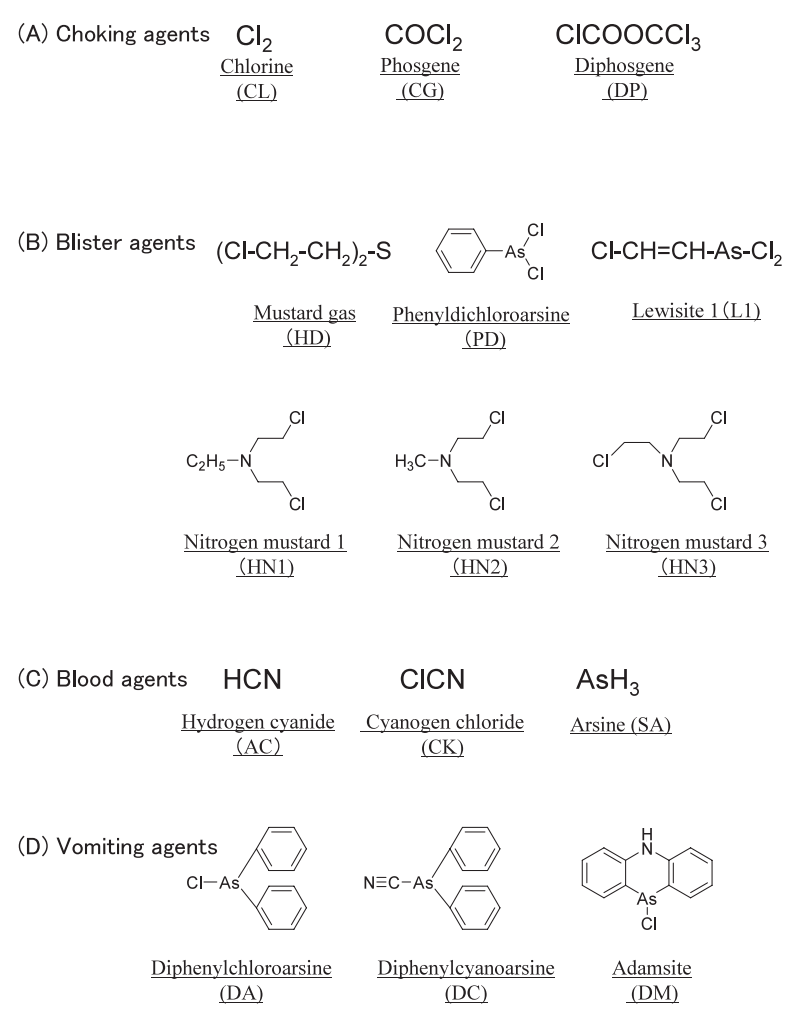

Fig. 1. Chemical Structure of CWAs, except Nerve Gases

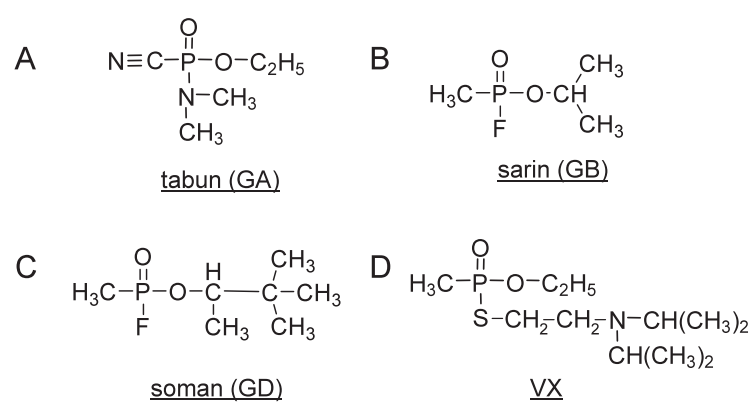

Fig. 2. Chemical Structures of Nerve Gases

mandating their destruction was ratified (1992) and has come into force (1997).

Since they readily decompose, it is difficult to detect CWAs themselves, especially in biological samples obtained from victims. Therefore, detection and identification of their degradation products is a more realistic manner in which to verify exposure to CWAs. In forensic chemistry and toxicology, mass spectrometry (MS) is widely used to demonstrate exposure to toxic substances. ${ }^{2,3)}$ The decomposition products are mostly water-soluble and non-volatile compounds, therefore, derivatization is indispensable for gas chromatography (GC) and GC-MS analysis. Nerve gases rapidly hydrolyze to alkyl methylphosphonic acids (AMPAs), ${ }^{4)}$ finally producing methylphosphonic acid (MPA). Our laboratory has adopted tertbutyldimethylsilylation to derivatize CWA decomposition products. AMPAs and MPA can be detected in environmental ${ }^{5,6)}$ and biological ${ }^{7,8)}$ samples. Thiodiglycol (a degradation product of mustard gas) and ethanolamines (degradation products of nitrogen mustards) can also be detected. ${ }^{9,10)}$

However, it is difficult to detect CWA decomposition products in a victim's blood, because the blood half-lives of these low-molecular-weight compounds are not long, and most components of CWAs are bound to biological macromolecules such as proteins and nucleic acids. CWAs have an electrophilic nature, and covalently react with nucleophilic compounds in the body (Fig. 3). In fact, we were not able to detect sarin hydrolysis products from all of the victims in the Tokyo subway sarin attack. ${ }^{11)}$ The covalently bound compounds that are formed from xenobiotics and biological macromolecules are called adducts. Adduct analysis has stolen the limelight as a method of demonstrating exposure to CWAs. In this mini review, we describe the present state of research on analytical methods for identifying CWA adducts, and introduce our own research on nerve gas adducts.

\section{ANALYSIS OF NERVE GAS ADDUCTS}

\section{Indirect Analysis}

Nervous system acetylcholinesterase (AChE, enzyme code (EC) 3.1.1.7) is the target enzyme for organophosphorus compounds (including nerve gases), and the inhibition of brain AChE activity leads to the disturbance of neurotransmission and toxicity. AChE and butyrylcholinesterase (BuChE, EC 3.1.1.8), are serine esterases in which the active center contains a serine residue and a related charge relay system. ${ }^{12)}$ Organophosphorus anti-cholinesterase agents irreversibly phosphorylate these serine residues. ${ }^{13)}$ Therefore, inhibited cholinesterases (ChEs), ChE adducts seem ideal candidates for verifying nerve gas exposure, because of the long-term presence of adduct proteins in a victim's blood. Polhuijs et al. ${ }^{14)}$ have verified sarin exposure by detecting sarin in blood samples from victims of the Matsumoto sarin gas attack, using GC-MS through regeneration of sarin from isopropylmethylphosphonylated $\mathrm{BuChE}$ with excess fluoride ion. Nagao et al. ${ }^{15)}$ have also verified sarin 
Analyte

(1) Intact CWA
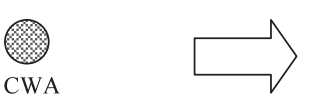

Go MS

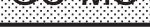

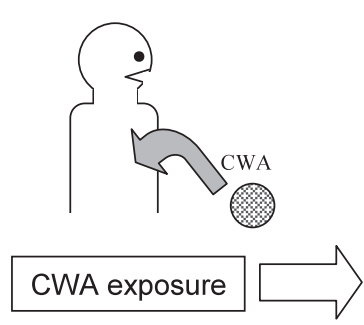

(2)

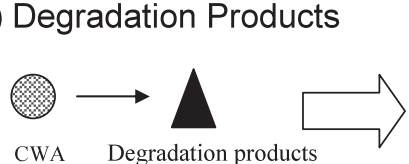

Analytical methods

(3) Adduct formation
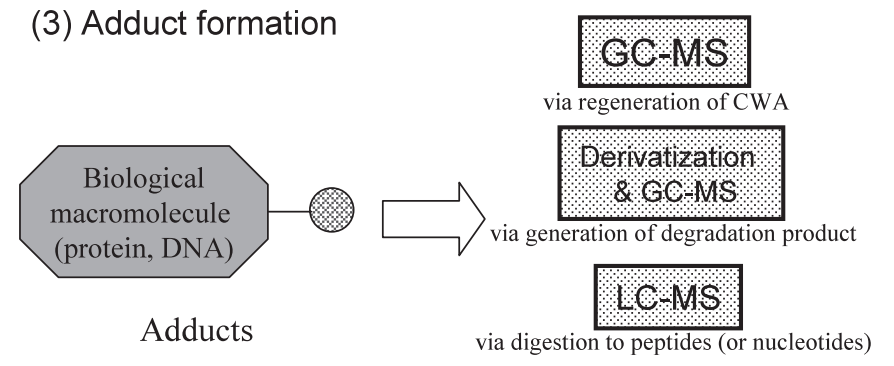

MALOr

Direct analysis

Fig. 3. Schematic Diagram of Changes in CWAs after Exposure and the Corresponding Analytical Methodology

exposure by detecting isopropylmethylphosphonic acid (IMPA) in blood samples from victims of the Tokyo subway sarin gas attack, using GC-MS through immunoaffinity purification of erythrocyte AChE adducts and IMPA liberation by phosphatase. These two methods using GC-MS are indirect methods for demonstrating CWA exposure.

\section{Direct Analysis}

When high-molecular-weight molecules such as proteins are measured by MS, the influence of the natural isotope distribution cannot be disregarded. There was a peak overlap between native AChE and sarin-inhibited AChE upon MS. ${ }^{16)}$ To overcome inefficient mass separation between natural and adduct proteins, liquid chromatography (LC)MS with protease digestion has been developed. Barak et al. ${ }^{16)}$ have demonstrated the direct detection of sarin and soman adducts of human recombinant $\mathrm{AChE}$ using matrix-assisted laser desorption ionization-time of flight (MALDI-TOF) MS. Noort et al. ${ }^{17)}$ have established the biomonitoring method of CWA exposure by detecting adducts of biological macromolecules using LC-MS. Fidder et al. ${ }^{18)}$ have reported the analysis of human $\mathrm{BuChE}$ adducts using LC-MS to verify nerve gas exposure, by which human BuChE was purified by procainamide affinity chromatography, and the active center nonapeptide was detected as an adduct marker after pepsin digestion. Other BuChE-Organization for the Prohibition of Chemical Weapons (OPCW) Schedule 1 nerve gas adducts have also been analyzed. ${ }^{19)}$

Recently, tandem MS with a capillary LC and electrospray ionization (ESI) ion source or postsource decay MALDI-TOF MS has been used widely for peptide sequencing of protein digests in proteome research. ${ }^{20)}$ Identification of the protein is possible by the integration of sequence information on the obtained peptide segments.

Blood samples are suitable for proving nerve gas exposure, because they can be collected not only from fatal cases, but also from patients without severe symptoms. In blood, there are two kinds of ChEs, membrane-bound erythrocyte AChE and 
soluble serum BuChE. To analyze the erythrocyte $\mathrm{AChE}$, a complicated solubilization procedure is necessary. On the other hand, serum BuChE does not require such solubilization pretreatment. Blood $\mathrm{BuChE}$ and $\mathrm{AChE}$ concentrations were reported to be about $80 \mathrm{nM}^{21)}$ and $20-40 \mathrm{nM}^{22)}$ Therefore, it is advantageous to select BuChE as the analytical target.

It is impossible to detect adducts in whole blood by LC-MS after protease digestion, because the blood BuChE concentration is very low and other blood proteins such as albumin and globulin obstruct the analysis. To increase the purity of blood $\mathrm{BuChE}$, we adopted procainamide affinity chromatography and sodium dodecylsulfate polyacrylamide gel electrophoresis (SDS-PAGE) pretreatment procedures, and succeeded in identifying phosphorylated BuChE using LC-MS.

The selection of protease is important in obtaining appropriate peptide fragments using LC-MS and LC-MS/MS. To identify the peptide sequence by LC-MS/MS, the ideal molecular weight of the peptide fragments is $m / z 600-1500$. Indeed, it is difficult to identify peptide sequences that have a molecular weight of $>3000$, because all the b- and y-series fragment ions are not necessarily obtained. Trypsin cleaves peptide chains at the carboxyl side of the basic amino acids lysine and arginine, and it has been used mainly as the protease for digestion of proteome analysis. The amino acid sequence of human serum BuChE and the active center serine residue have already been identified. ${ }^{23}$ ) Thus the sequence of active center serine residue containing peptide and its monoisotopic mass after proteolytic digestion can be predicted. Diisopropylfluorophosphate (DFP)-inhibited $\alpha$-chymotrypsin could be digested by trypsin to produce active center pentacosapeptide (DAMICAGASGVSSCMGDS*GGPLVCK; monoisotopic mass of protonated acrylamidemodified non-inhibited peptide is 2529.1), and the peptide sequence was identified. ${ }^{24)}$ Tryptic digest of $\mathrm{BuChE}$ has been predicted to produce active center nonacosapeptide (SVTLFGES*AGAASVSLHLLSPGSHSLFTR; monoisotopic mass of protonated acrylamide-modified non-inhibited peptide is 2928.5), which seemed difficult to analyze by LC-MS. Indeed, we could not detect that peptide from a tryptic digest of BuChE.

Fidder et al. ${ }^{18)}$ have digested BuChE using pepsin, and have obtained the nonapeptide. We have used chymotrypsin for BuChE digestion, ${ }^{25}$ )
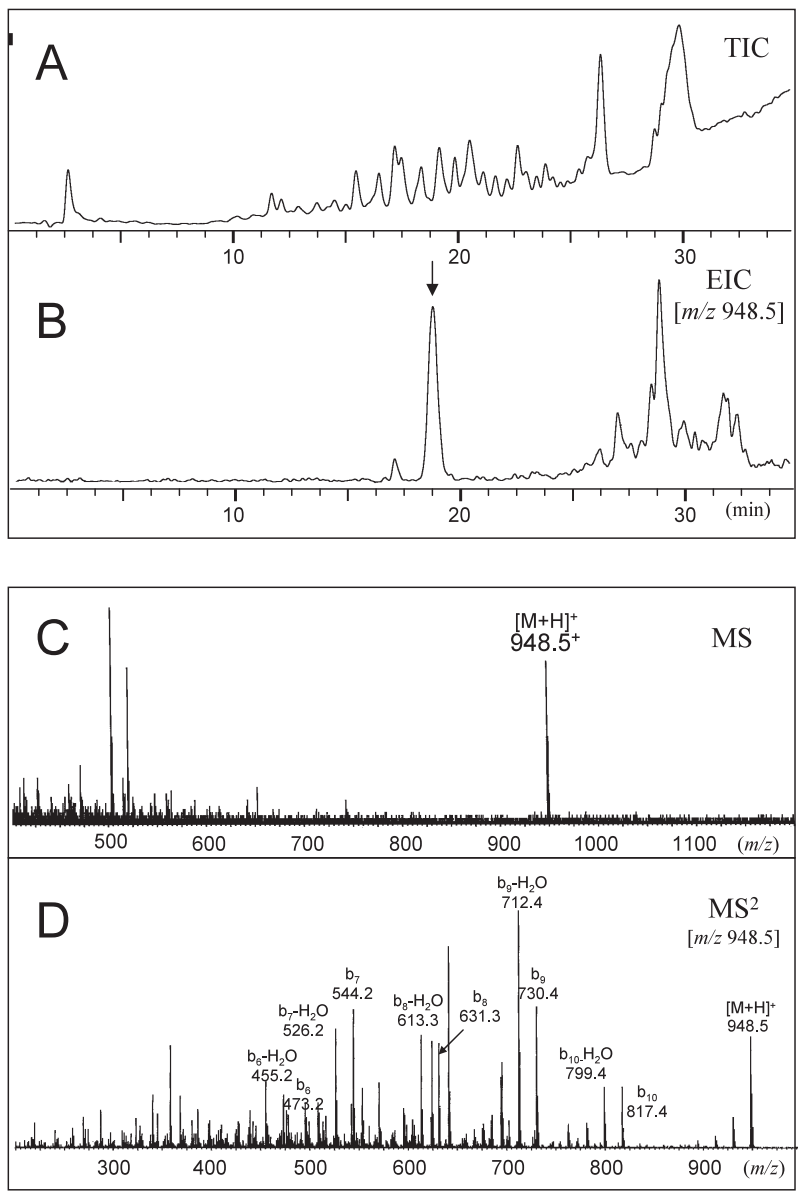

Fig. 4. Total and Extracted Ion Chromatograms of Chymotryptic Digest of Untreated Human BuChE

A: total ion chromatogram. B: extracted ion chromatogram at $m / z$ 948.5. LC-MS measurement was carried out using Micromass QTOF2 equipped with Agilent 1150 HPLC system using CrestPak C18S (JASCO, Tokyo, Japan, $\phi=2.2 \mathrm{~mm}, \mathrm{~L}=150 \mathrm{~mm}$ ) column. mobile phase; $\mathrm{H}_{2} \mathrm{O}$-acetonitrile (contains $0.1 \%$ formic acid) gradient elution. MS condition: Electrospray Ionizaion $(\mathrm{ESI})(+)$; capillary voltage $+3 \mathrm{kV}$; cone voltage $35 \mathrm{~V}$; nebulizer gas: $\mathrm{N}_{2} 250^{\circ} \mathrm{C}$; MS/MS condition: collision gas: Ar; collision energy $20-45 \mathrm{eV}$.

because we considered the substrate specificity of chymotrypsin and pepsin. Chymotrypsin cleaves peptide bonds at the carboxyl side of aromatic amino acids (tyrosine, tryptophan and phenylalanine). Under appropriate reaction conditions of reaction time and temperature, chymotrypsin also hydrolyzes other amide bonds, particularly those with leucine-donated carboxyl residues. When human BuChE is digested by chymotrypsin, the expected peptide-containing active serine residue is "GES $\boldsymbol{S}^{*}$ AGAASVSL" ( $\mathbf{S}^{*}$ denotes active serine residue) and the monoisotopic mass is calculated at 947.5. From the LC-MS analysis of chymotryptic digests of untreated human $\mathrm{BuChE}$, one peak eluted at $19.0 \mathrm{~min}$ was detected on the extracted ion chromatogram at $\mathrm{m} / z \quad 948.5$ (Fig. 4B), 


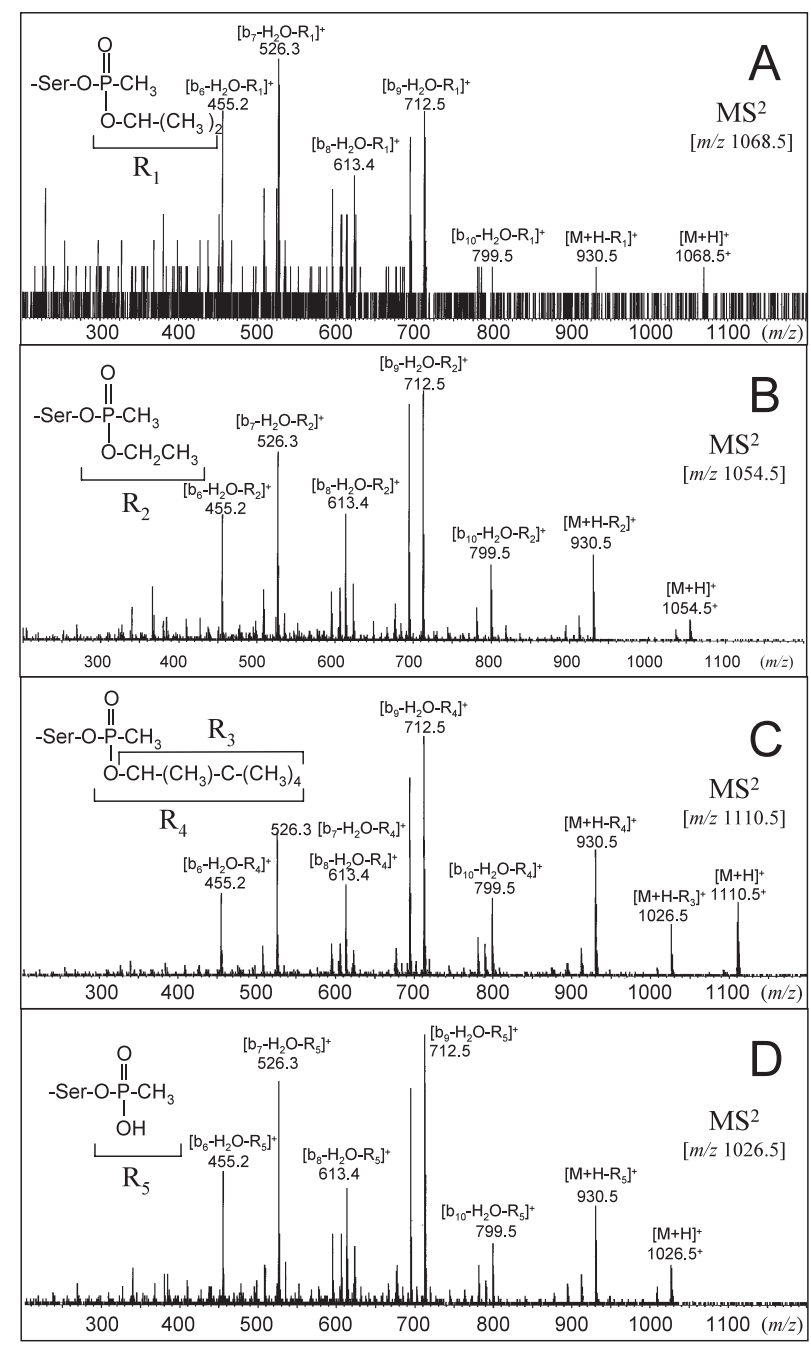

Fig. 5. Product Ion Mass Spectra of Peptide Fragments Containing Active Center Serine

A: sarin adduct $(m / z$ 1068.5). B: VX adduct $(m / z$ 1054.5). C: soman adduct $(m / z$ 1110.5). D: soman adduct, aged enzyme $(\mathrm{m} / \mathrm{z}$ 1026.5). MS/MS condition: collision gas; Ar.

and the sequence was ascertained by MS/MS analysis (Fig. 4C and 4D). In addition, Fig. 4A shows the total ion chromatogram. The adduct of human serum BuChE with nerve gases (sarin, soman or $\mathrm{VX}$ ) produced corresponding nerve-gas-combined active center peptides. From the digest of the human BuChE-sarin adduct, a singly charged peptide peak was detected on the extracted ion chromatogram at $m / z 1068.5$ (Fig. 5A), and the sequence was ascertained to be "GEXAGAASVSL" by MS/MS analysis (X denotes isopropylmethylphosphonylated serine). The difference in molecular weight (120.0 Da) between the active center peptide fragments that corresponded to the untreated $\mathrm{BuChE}$ and $\mathrm{BuChE}$ sarin adduct was assumed to be derived from the addition of an isopropyl methylphosphonyl moiety to

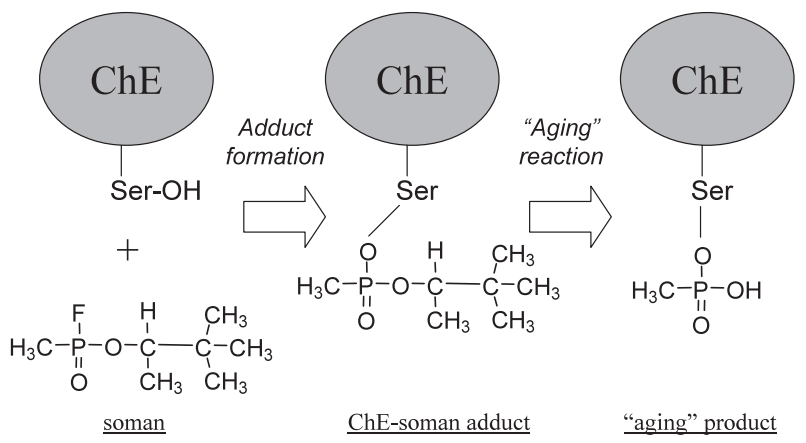

Fig. 6. Schematic Diagram of Nerve Gas-ChE Adduct Formation and Its "Aging" Reaction

the active serine residue. The formation of human BuChE adducts with VX has also been confirmed (Fig. 5B). It is known that alkyl ester residues are eliminated from nerve gas-ChE adducts by a nonenzymatic reaction. This is called the aging reaction (Fig. 6) ${ }^{26,27)}$. The aging speed of the soman-ChE adduct is the fastest of the nerve gas-ChE adducts, and the half-life of rat AChE-soman adduct is estimated to be $10 \mathrm{~min} .{ }^{28)}$ Soman adduct and its aging product have been detected and their sequences ascertained (Fig. 5C and 5D). The inhibition level of the enzymatic activity was well correlated with the content ratio of the adduct peptide to non-adduct peptide. The peak area of the VX-combined peptide increased in proportion to the inhibition levels of the enzymatic activity (Fig. 7). The detection limit of BuChE was estimated at $4 \mathrm{ng} /$ injection (53 fmol/injection). Therefore, considering from the sensitivity of this MS analysis, if we can prepare the 5-ml blood samples, the minimum detectable inhibition level was presumed to be able to detect $1 \%$ inhibition.

Usage of nerve gases in usual laboratories is legally restricted, and so the authentic adduct samples are not available. Instead, synthesis and usage of the nerve gas-adduct peptides are not legally restricted. We are now developing a method to synthesize adduct peptides which can be usable as authentic compounds for protease digestion LC-MS analysis.

\section{ANALYSIS OF MUSTARD GAS AND NITROGEN MUSTARD ADDUCTS}

The blister agent sulfur mustard has two chlorine atoms with high reactivity, and forms an adduct with biological macromolecules via electrophilic 

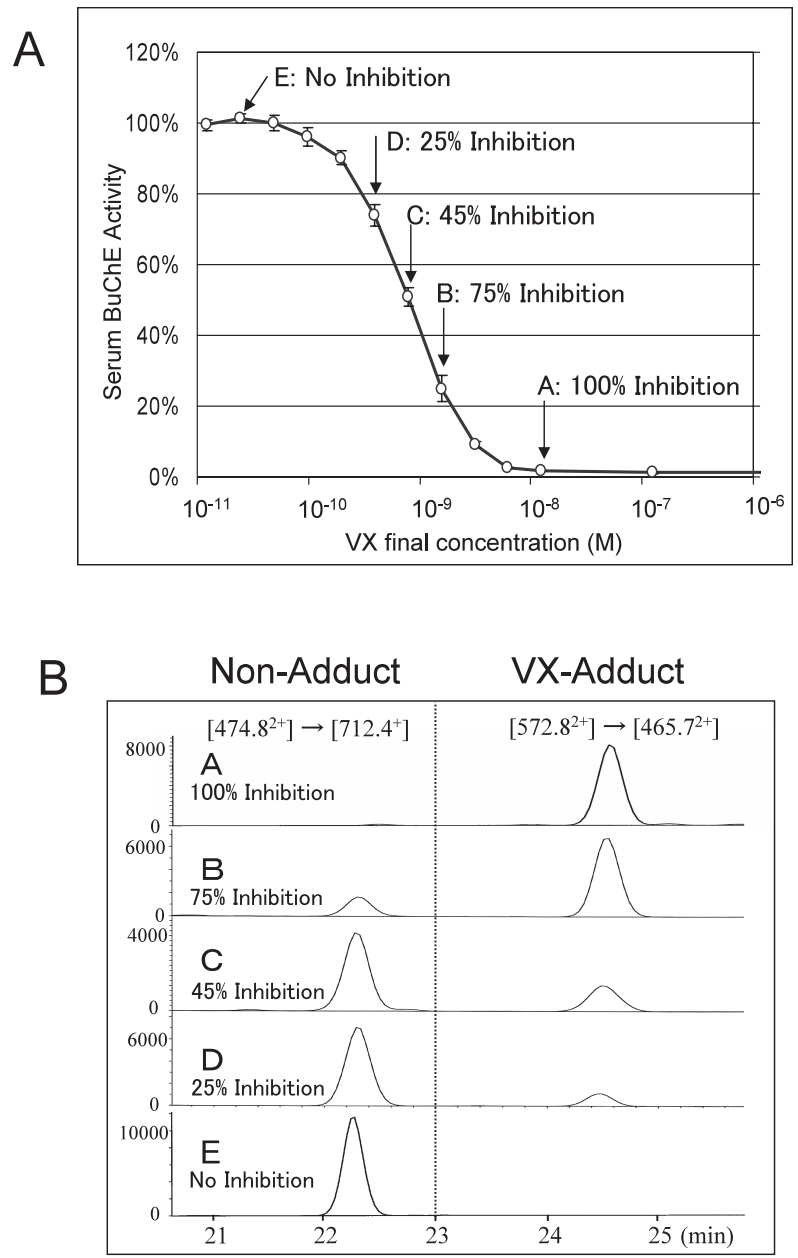

Fig. 7. Correlation between BuChE Activity Inhibition and Adduct Formation

A: Inhibition curve for human serum BuChE with VX. BuChE activity was measured by Ellman's 5,5'-Dithiobis (2-nitrobenzoic acid) (DTNB) spectrophotometric method. B: Multiple Reaction Monitoring (MRM) chromatograms of human serum $\mathrm{BuChE}$ with various inhibition state after chymotryptic digestion. LC-MS was carried out using Agilent LC-MSD Trap equipped with 1100 HPLC system using Zorabax SB $\mathrm{C}_{18} 300 \mathrm{~A}$ (Agilent $\phi=0.5 \mathrm{~mm}, \mathrm{~L}=150 \mathrm{~mm}$ ) column, and mobile phase; $\mathrm{H}_{2} \mathrm{O}$-acetonitrile (contains $0.1 \%$ formic acid) gradient elution, MS condition: $\mathrm{ESI}(+)$; capillary voltage $+3 \mathrm{kV}$; nebulizer gas: $\mathrm{N}_{2} 300^{\circ} \mathrm{C} 8.0 \mathrm{~L} / \mathrm{min}, \mathrm{MS} / \mathrm{MS}$ condition: collision gas; He.

alkylation. This alkylation is non-specific, compared with specific nerve gas-ChE adduct formation. Fidder et al. have shown that mustard gas combines with the $\mathrm{N}$-terminal valine residue of human hemoglobin, by detecting the mustard gasvaline adduct, using GC-MS under negative ionization after modified Edman degradation and heptafluorobutyric derivatization. ${ }^{29)}$ Other mustard gas adducts, cysteine, aspartic acid, glutamic acid and histidine adduct, have also been found for human hemoglobin. ${ }^{30,31)}$ Mustard gas has been shown to alkylate a cysteine residue in human serum albumin, and the alkylation site was identified in a tryptic digest of mustard-gas-exposed albumin. ${ }^{32)}$ From an in vitro experiment using $\left[{ }^{14} \mathrm{C}\right]$-labeled mustard gas and cultured human cells, $15-20 \%$ of radioactivity was combined with keratin. ${ }^{33)}$ A time course study of the mustard gas adduct showed that the albumin adduct (S-2-hydroxyethylthioethyl)-Cys-ProTyr was detected until 7 days after exposure, and the N-terminal valine adduct in hemoglobin was detected after 28 days. ${ }^{34)}$ This result indicates the possibility of detection of mustard gas adduct for a comparatively long time. Benschop et al. have reported that the mustard gas $\mathrm{N}^{7}$-guanine adduct was detected from the lymphocytes and granulocytes of victims from the Iran-Iraq conflict. ${ }^{35)}$ The reaction mechanisms of nitrogen mustard with biological macromolecules are non-specific, similar to those of mustard gas. ${ }^{36)}$ Osborne et al. have reported that nitrogen mustard 2 (HN2) reacts with DNA, which produces $\mathrm{N}^{7}$-guanine and $\mathrm{N}^{3}$-adenine adducts. In addition, crosslinking by $\mathrm{HN} 2$ of guanine to guanine or guanine to adenine has been observed. $^{37)}$

\section{ANALYSIS OF PHOSGENE ADDUCTS}

The choking agent phosgene does not have strong toxicity compared with nerve agents, but because of its use as an important intermediate in the chemical industry, very large amounts of phosgene are produced and stockpiled all over the world. Noort et al. have reported the characterization of phosgene-globulin adduct and phosgene-serum albumin adduct using micro-LC-MS/MS analysis after the tryptic and V8 protease digestion. This report showed that phosgene binds to globin and serum albumin in vitro ${ }^{38)}$ through crosslinking at lysine residues by an urea-type chemical bond. Phosgene is metabolically generated after exposure to chloroform and combines with phospholipids. ${ }^{39)}$

\section{CONCLUSION}

We described MS for retrospective verification of exposure to CWAs by detecting adduct molecules. CWA adducts remain in the body for a longer period than the agents themselves, and detecting these adducts is very strong proof of CWA exposure. 


\section{REFERENCES}

1) Society for Countermeasure against Chemical, Biological, Radiological, Nuclear and Explosive Terrorism (2008) Nuclear, Biological and Chemical Terrorism Countermeasure Handbook, Shindan To Chiryo Sha, Tokyo.

2) Wood, M., Laloup, M., Samyn, N., del Mar Ramirez Fernandez, M., de Bruijn, E. A., Maes, R. A. A. and De Boeck, G. (2006) Recent applications of liquid chromatography-mass spectrometry in forensic science. J. Chromatogr. A, 1130, 3-15.

3) Seto, Y., Kanamori, M. and Tsuge, K. (2008) Mass spectrometric technologies for countering chemical and biological terrorism incidents. J. Mass Spectrom. Soc. Jpn., 56, 91-115.

4) Verweij, A. and Boter, H. L. (1979) Chemical Warfare Agents: Verification of Compounds Containing the Phosphorus-Methyl Linkage in Waste Water. Science, 204, 616-618.

5) Kataoka, M., Tsunoda, N., Ohta, H., Tsuge, K., Takesako, H. and Seto, Y. (1998) Effect of cationexchange pretreatment of aqueous soil extracts on the gas chromatographic-mass spectrometric determination of nerve agent hydrolysis products after tert-butyldimethylsilylation. J. Chromatogr. A, 824, 211-221.

6) Kanamori-Kataoka, M. and Seto, Y. (2008) Laboratory Identification of the Nerve Gas Hydrolysis Products Alkyl Methylphosphonic Acids and Methylphosphonic Acid, by Gas Chromatography-mass Spectrometry after tert-Butyldimethylsilylation. J. Health Sci., 54, 513-523.

7) Kataoka, M. and Seto, Y. (2003) Discriminative determination of alkyl methylphosphonates and methylphosphonate in blood plasma and urine by gas chromatography-mass spectrometry after tert-butyldimethylsilylation. J. Chromatogr. B Biomed. Appl., 795, 123-132.

8) Tsuchihashi, H., Katagi, M., Nishikawa, M. and Tatsuno, M. (1998) Identification of metabolites of nerve agent VX in serum collected from a victim. $J$. Anal. Toxicol., 22, 383-388.

9) Ohsawa, I., Kanamori-Kataoka, M., Tsuge, K. and Seto, Y. (2004) Determination of nitrogen mustard hydrolysis products, ethanolamines by gas chromatography-mass spectrometry after tertbutyldimethylsilyl derivatization. J. Chromatogr. A, 1061, 235-241.

10) Ohsawa, I. and Seto, Y. (2006) Determination of nitrogen mustard hydrolysis products, ethanolamines by gas chromatography-mass spectrometry af- ter tert-butyldimethylsilyl derivatization. J. Chromatogr. A, 1122, 242-248.

11) Seto, Y., Tsunoda, N., Kataoka, M., Tsuge, K. and Nagano, T. (1999) Toxicological Analysis of Victim's Blood and Crime Scene Evidence Samples in the Sarin Gas Attack cause by the Aum Shinrikyo Cult. In Natural and selected synthetic toxinsBiological implications (Tu, A. A. and Gaffield, W., Eds.), pp. 318-332, American Chemical Society, Washington D.C., U.S.A.

12) Blow, D. M., Birktoft, J. J. and Hartley, B. S. (1969) Role of a buried acid group in the mechanism of action of chymotrypsin. Nature, 221, 337-340.

13) Thompson, A. R. and Ellin, R. I. (1970) Decreased reactivity of organophosphorus inhibitors towards a modified chymotrypsin. Biochim. Biophys. Acta, 220, 101-107.

14) Polhuijs, M., Langenberg, J. P. and Benschop, H. P. (1997) New method for retrospective detection of exposure to organophosphorus anticholinesterases: application to alleged sarin victims of Japanese terrorists. Toxicol. Appl. Pharmacol., 146, 156-161.

15) Nagao, M., Takatori, T., Matsuda, Y., Nakajima, M., Iwase, H. and Iwadate, K. (1997) Definitive evidence for the acute sarin poisoning diagnosis in the Tokyo subway. Toxicol. Appl. Pharmacol., 144, 198-203.

16) Barak, R., Ordentlich, A., Barak, D., Fischer, M., Benschop, H. P., de Jong, L. P. A., Segall, Y., Velan, B. and Shafferman, A. (1997) Direct determination of the chemical composition of acetylcholinesterase phosphonylation products utilizing electrospray-ionization mass spectrometry. FEBS Lett., 407, 347-352.

17) Noort, D., Benschop, H. P. and Black, R. M. (2002) Biomonitoring of exposure to chemical warfare agents: a review. Toxicol. Appl. Pharmacol., 184, 116-126.

18) Fidder, A., Hulst, A. G., Noort, D., de Ruiter, R., van der Schans, M. J., Benschop, H. P. and Langenberg, J. P. (2002) Retrospective detection of exposure to organophosphorus anti-cholinesterases: mass spectrometric analysis of phosphylated human butyrylcholinesterase. Chem. Res. Toxicol., 15, 582-590.

19) Van der Schans, M. J., Fidder, A., van Oeveren, D., Hulst, A. G. and Noort, D. (2008) Verification of exposure to cholinesterase inhibitors: generic detection of OPCW Schedule 1 nerve agent adducts to human butyrylcholinesterase. J. Anal. Toxicol., 32, 125-130.

20) Aebersold, R. and Goodlett, D. R. (2001) Mass spectrometry in proteomics. Chem. Rev., 101, 269295. 
21) Myers, D. K. (1952) Studies on cholinesterase. 7: Determination of the molar concentration of pseudocholinesterase in serum. Biochem. J., 51, 303-311.

22) MacQueen, J., Plaut, D., Borges, J. and Anido, G. (1971) Manual colorimetric methods for pseudocholinesterase and red cell (true) cholinesterase. Clin. Chem., 17, 481-485.

23) Lockridge, O., Bartels, C. F., Vaughan, T. A., Wong, C. K., Norton, S. E. and Johnson, L. L. (1987) Complete amino acid sequence of human serum cholinesterase. J. Biol. Chem., 262, 549-557.

24) Tsuge, K. and Seto, Y. (2002) Analysis of organophosphorus compound adducts of serine proteases by liquid chromatography-tandem mass spectrometry. J. Chromatogr. B Analyt. Technol. Biomed. Life Sci., 776, 79-88.

25) Tsuge, K. and Seto, Y. (2006) Detection of human butyrylcholinesterase-nerve gas adducts by liquid chromatography-mass spectrometric analysis after in gel chymotryptic digestion. J. Chromatogr. B Analyt. Technol. Biomed. Life Sci., 838, 21-30.

26) Shafferman, A., Ordentlich, A., Barak, D., Stein, D., Ariel, N. and Velan, B. (1996) Aging of phosphylated human acetylcholinesterase: catalytic processes mediated by aromatic and polar residues of the active centre. Biochem. J., 318, 833-840.

27) Fleisher, J. H. and Harris, L. W. (1965) Dealkylation as a mechanism for aging of cholinesterase after poisoning with pinacolyl methylphosphonofluoridate. Biochem. Pharmacol., 14, 641-665.

28) Talbot, B. G., Anderson, D. R., Harris, L. W., Yarbrough, L. W. and Lennox, W. J. (1988) A comparison of in vivo and in vitro rates of aging of soman-inhibited erythrocyte acetylcholinesterase in different animal species. Drug Chem. Toxicol., 11, 289-305.

29) Fidder, A., Noort, D., de Jong, A. L., Trap, H. C., de Jong, L. P. A. and Benschop, H. P. (1996) Monitoring of in vitro and in vivo exposure to sulfur mustard by GC/MS determination of the N-terminal valine adduct in hemoglobin after a modified Edman degradation. Chem. Res. Toxicol., 9, 788-792.

30) Noort, D., Hulst, A. G., Trap, H. C., de Jong, L. P. A. and Benschop, H. P. (1997) Synthesis and Mass Spectrometric Identification of the Major Amino Acid Adducts Formed between Sulphur Mustard and Haemoglobin in Human Blood. Arch. Toxicol., 71, 171-178.

31) Black, R. M., Clarke, R. J., Harrison, J. M. and Read, R. W. (1997) Biological fate of sulphur mustard: identification of valine and histidine adducts in haemoglobin from casualties of sulphur mustard poisoning. Xenobiotica, 27, 499-512.

32) Noort, D., Hulst, A. G., de Jong, L. P. A. and Benschop, H. P. (1999) Alkylation of human serum albumin by sulfur mustard in vitro and in vivo: mass spectrometric analysis of a cysteine adduct as a sensitive biomarker of exposure. Chem. Res. Toxicol., 12, 715-721.

33) Noort, D., Fidder, A., Hulst, A. G., de Jong, L. P. A. and Benschop, H. P. (2000) Diagnosis and dosimetry of exposure to sulfur mustard: development of a standard operating procedure for mass spectrometric analysis of haemoglobin adducts: exploratory research on albumin and keratin adducts. J. Appl. Toxicol., 20 Suppl. 1, S187-S192.

34) Noort, D., Fidder, A., Degenhardt-Langelaan, C. E. and Hulst, A. G. J. (2008) Retrospective detection of sulfur mustard exposure by mass spectrometric analysis of adducts to albumin and hemoglobin: an in vivo study. J. Anal. Toxicol., 32, 25-30.

35) Benschop, H. P., Schans, G. P., Noort, D., Fidder, A. and de Jong, L. P. A. (1997) Verification of Exposure to Sulfur Mustard in Two Casualties of the Iran-Iraq Conflict. J. Anal. Toxicol., 21, 249-251.

36) Mattes, W. B., Hartley, J. A. and Kohn, K. W. (1986) DNA sequence selectivity of guanine-N7 alkylation by nitrogen mustards. Nucleic Acids Res., 14, 29712987.

37) Osborne, M. R., Wilman, D. E. and Lawley, P. D. (1995) Alkylation of DNA by the nitrogen mustard bis(2-chloroethyl)methylamine. Chem. Res. Toxicol., 8, 316-320.

38) Noort, D., Hulst, A. G., Fidder, A., van Gurp, R. A., de Jong, L. P. A. and Benschop, H. P. (2000) In Vitro Adduct Formation of Phosgene with Albumin and Hemoglobin in Human Blood. Chem. Res. Toxicol., 13, 719-726.

39) Di Consiglio, E., De Angelis, G., Testai, E. and Vittozzi, L. (2001) Correlation of a specific mitochondrial phospholipid-phosgene adduct with chloroform acute toxicity. Toxicology, 159, 43-53. 